\title{
Study ON THe Properties of PTMG TOUGHENER MODIFIED EPOXY RESINS
}

\author{
Chenrui Shao \\ Hangzhou Foreign Languages School, China
}

\section{ABSTRACT}

The E-51 epoxy resin was modified by PTMG toughener. The resin was cured under high temperature, with methyl tetrahydrophthalic anhydride (MeTHPA) as the curing agent and 2,4,6Tris(dimethylaminomethyl)phenol (DMP-30) as the curing accelerator. Dynamic Mechanic Analysis data shows that PTMG significantly reduced the glass transition temperature of cured material. Impact strength test results shows that the presence of PTMG in the cured material increased its impact strength. The maximum impact strength was achieved while the mass fraction of PTMG is $12 \%$. Tensile strength, tensile modulus, flexural strength, and flexural modulus data indicates that the while the mass fraction was smaller than the valve value, PTMG increased the cured material's tensile and flexural strength as well as its tensile and flexural modulus. While the mass fraction of PTMG was larger than the valve value, the increase of the mass fraction of PTMG reduced the cured material's strength and modulus.

\section{KEYWORDS}

Toughener, Epoxy Resin, PTMG

\section{INTRODUCTION}

As they are highly crosslinked polymers, epoxy resins often offer a wide range of favorable mechanical properties as well as the property of high thermal and chemical resistance. The fact that epoxy resins have a weak resistance to impact makes it favorable to finding a toughener for them. Extension of the macromolecular chains in the epoxy resins by introducing long chain alkane polymers can improve the macromolecular chains' ability to absorb impact energy. Under this principle, the introduction of PTMG in the macromolecular chains will improve the epoxy resins' ability to withstand impact. The curing mechanism is shown in Figure 1.

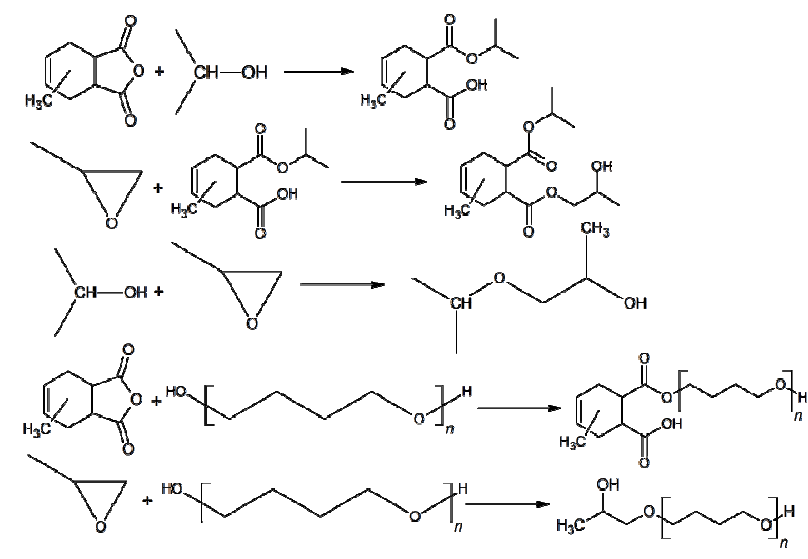

Figure 1. A brief explanation of the curing mechanism

DOI: $10.5121 /$ ijac.2019.5101 
Previous work have shown that polyurethane modified TDE-85 epoxy resin has a significantly better tensile strength and impact strength than original TDE-85 epoxy (Ref. [4] and the same author's work on this topic), and the presence of HCCP-OA-DGEBA in DGEBA epoxy resin has increased for about $150 \%$ when the weight ratio of HCCP-OA-DGEBA is $5 \%$ of the weight of the resin (Ref. [3]). It has been observed that the polymer formed by PTMG and epoxy resin mixture may have the similar polymer structure as the two polymers mentioned above. This suggests that the introduction of PTMG can improve the material's fracture toughness.

In the work reported in this study, a series of examinations about how the introduction and the weight ratio of a new toughener, Polytetrahydrofuran-400 (PTMG-400), in E-51 epoxy resin affect the epoxy resin's physical properties was conducted, and the physical properties of the epoxy resins with different toughener content was measured.

\section{EXPERIMENT}

\subsection{EXPERIMENT INGREDIENTS}

E-51 epoxy resinwas provided by Yueyang Sinopec Baling Petrochemical Company. Methyl tetrahydrophthalic anhydride (MeTHPA) was provided by Jiaxing Dongfang Chemical Plant. 2,4,6-Tris(dimethylaminomethyl)phenol (DMP-30) was provided by Shanghai Aladdin BioChem Technology Co.,LTD. Polytetrahydrofuran-400 (PTMG-400) was provided by Jinan Baichuan Chemical Plant.

\subsection{EXPERIMENT DEVICES}

HOC-GWX60C high temperature drying oven, Shanghai Hocheck Electronic Technology CO., LTD.

DF 101S collector-type constant temperature magnetic stirrer, Shanghai Jukun Equipment CO., LTD.

M08 Mirror Glaze Maximum Mold Release Wax, Meguiar's.

\subsection{Synthesis Of CURED EPOXY RESIN MIXTURE}

The E-51 epoxy resin was mixed with the methyl tetrahydrophthalic anhydride (MeTHPA). The mole ratio between E-51 epoxy resin and the MeTHPAwas1:1. Polytetrahydrofuran-400 (PTMG400) was then added into the epoxy resin mixture according to the formulas listed in Table 1 . The mixture was stirred under $60^{\circ} \mathrm{C}$ for 1 hour.Then, the curing accelerator, DMP-30, was added into the mixture. The resin mixture was stirred continuously until it became a transparent yellow solution. After the stirring stopped, the mixture was added into the mold and cured in the hightemperature drying oven following a heating procedure: $\left(100^{\circ} \mathrm{C}, 4 \mathrm{~h} \rightarrow 150^{\circ} \mathrm{C}, 2 \mathrm{~h}\right)$. After the curing process, moldwas cooled down to the room temperature to demold the cured modified epoxy resin.

Table 1. Formulas of the Cured Modified Epoxy Resin Mixture Samples

\begin{tabular}{cccccc}
\hline $\begin{array}{c}\text { Sample } \\
\text { Number }\end{array}$ & E-51(g) & $\begin{array}{c}\text { MeTHPA } \\
(\mathbf{g})\end{array}$ & PTMG(g) & $\begin{array}{c}\text { DMP- } \\
\text { 30 }(\mathbf{g})\end{array}$ & Mass ratio of ingredients \\
\hline S0 & $100 \mathrm{~g}$ & $84.7 \mathrm{~g}$ & $0 \mathrm{~g}$ & $2 \mathrm{~g}$ & $1: 0.847: 0.00: 0.02$ \\
S20 & $100 \mathrm{~g}$ & $84.7 \mathrm{~g}$ & $2 \mathrm{~g}$ & $2 \mathrm{~g}$ & $1: 0.847: 0.02: 0.02$ \\
$\mathrm{~S} 40$ & $100 \mathrm{~g}$ & $84.7 \mathrm{~g}$ & $4 \mathrm{~g}$ & $2 \mathrm{~g}$ & $1: 0.847: 0.04: 0.02$ \\
S60 & $100 \mathrm{~g}$ & $84.7 \mathrm{~g}$ & $6 \mathrm{~g}$ & $2 \mathrm{~g}$ & $1: 0.847: 0.06: 0.02$ \\
S80 & $100 \mathrm{~g}$ & $84.7 \mathrm{~g}$ & $8 \mathrm{~g}$ & $2 \mathrm{~g}$ & $1: 0.847: 0.08: 0.02$
\end{tabular}


International Journal of Advances in Chemistry (IJAC) Vol. 5, No.1, February 2019

\begin{tabular}{llllll}
$\mathrm{S} 100$ & $100 \mathrm{~g}$ & $84.7 \mathrm{~g}$ & $10 \mathrm{~g}$ & $2 \mathrm{~g}$ & $1: 0.847: 0.10: 0.02$ \\
$\mathrm{~S} 120$ & $100 \mathrm{~g}$ & $84.7 \mathrm{~g}$ & $12 \mathrm{~g}$ & $2 \mathrm{~g}$ & $1: 0.847: 0.12: 0.02$ \\
$\mathrm{~S} 140$ & $100 \mathrm{~g}$ & $84.7 \mathrm{~g}$ & $14 \mathrm{~g}$ & $2 \mathrm{~g}$ & $1: 0.847: 0.14: 0.02$ \\
$\mathrm{~S} 160$ & $100 \mathrm{~g}$ & $84.7 \mathrm{~g}$ & $16 \mathrm{~g}$ & $2 \mathrm{~g}$ & $1: 0.847: 0.16: 0.02$ \\
$\mathrm{~S} 180$ & $100 \mathrm{~g}$ & $84.7 \mathrm{~g}$ & $18 \mathrm{~g}$ & $2 \mathrm{~g}$ & $1: 0.847: 0.18: 0.02$ \\
S200 & $100 \mathrm{~g}$ & $84.7 \mathrm{~g}$ & $20 \mathrm{~g}$ & $2 \mathrm{~g}$ & $1: 0.847: 0.20: 0.02$ \\
\hline
\end{tabular}

\subsection{TeSting DeVices AND Methods}

1. Dynamic mechanical analysis (DMA): DMA data was measured on PerkinElmer Pyris Diamond DM, the standard size of the sample was $60 \mathrm{~mm} \times 10 \mathrm{~mm} \times 2 \mathrm{~mm}$. The heating rate was set to $2^{\circ} \mathrm{C} / \mathrm{min}$; start temperature was set to $40^{\circ} \mathrm{C}$; limit temperature was set to $210^{\circ} \mathrm{C}$.

2. Three-point bending flexural test: According to GB/T 2570-1995 standard, the bending flexural test data was measured by Shenzhen Reger Instrument Co., LTD. RGM-4036 Microcomputer control electronic universal testing machine. The loading speed was set to $2 \mathrm{~mm} / \mathrm{min}$

3. Tensile testing: According to GB/T 2568-1995 standard, the tensile testing data was measured by Shenzhen Reger Instrument Co., LTD. RGM-4036 Microcomputer control electronic universal testing machine. The loading speed was set to $4 \mathrm{~mm} / \mathrm{min}$.

4. Impact testing: According to GB/T 2571-1995 standard, the pendulum has the capacity of 7.5 Joules. The standard size of the sample was $120 \mathrm{~mm} \times 15 \mathrm{~mm} \times 10 \mathrm{~mm}$. There was no gap in the sample.

\section{ANALYSIS}

\subsection{DMa Properties}

The relationship between $\tan \delta$ data of the PTMG modified epoxy resins and its temperature is shown in Figure 2.

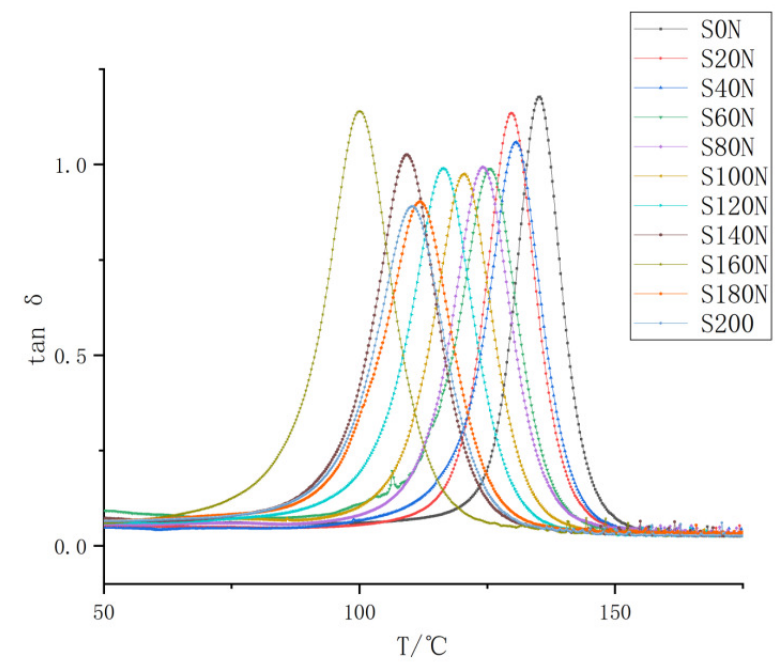

Figure 2. The DMA properties of the modified epoxy resins

It is commonly believed that the temperature of the point with maximum $\tan \delta$ data reflects the glass transition temperature ( $\mathrm{Tg}$ ) of the cured epoxy resin mixtures. According to Figure2, the 
glass transition temperature of the epoxy resin without the addition of PTMG was about $135.2^{\circ} \mathrm{C}$. While the mass of PTMG was less than $16 \%$ of the mass of E-51 epoxy resin, the glass transition temperature (Tg) significantly decreased as the mass of PTMG increased. When the mass ratio between PTMG and E-51 epoxy resin was 16:100, the glass transition temperature of the epoxy resin mixture was about $100.1{ }^{\circ} \mathrm{C}$. When the mass ratio between PTMG and E-51 epoxy resin was 18:100, the glass transition temperature rose to $110.5^{\circ} \mathrm{C}$, and the glass transition temperature was slightly decreased when the mass ratio between PTMG and E-51 epoxy resin was 20:100.

The decrease of the glass transition temperature (Tg) may be contributed to the introduction of long PTMG chains, which increased the flexibility of the macromolecular chains and can result in a decrease in the glass transition temperature of the epoxy resins.

\subsection{Dynamical Properties}

Figure 3 indicates the tensile strength and tensile modulus of the cured epoxy resin mixtures.
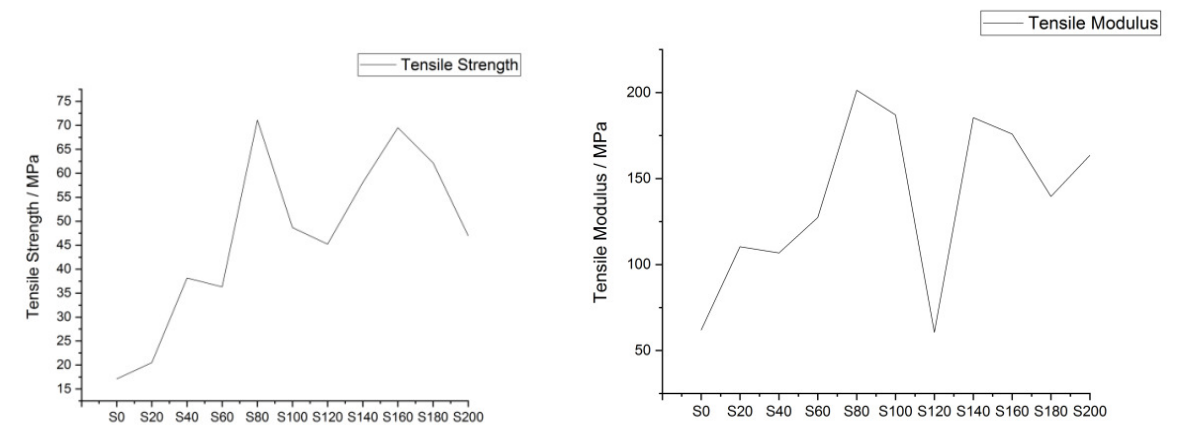

Figure 3. The tensile strength and tensile modulus of different modified epoxy resins

The data shows that the tensile strength and tensile modulus was significantly improved in the epoxy resin with PTMG added. While the mass of PTMG was $8 \%$ of the mass of epoxy resin, the tensile strength of the epoxy resin reached its maximum value of $71.108 \mathrm{MPa}$, and the tensile modulus reached its maximum value of $201.348 \mathrm{MPa}$. When the mass of PTMG was more than $8 \%$ of the epoxy resin, the tensile strength and the tensile modulus of the epoxy resin decreased as the mass percentage of PTMG increased.

Figure 4 indicates the bending strength and bending modulus of the cured epoxy resin mixtures.
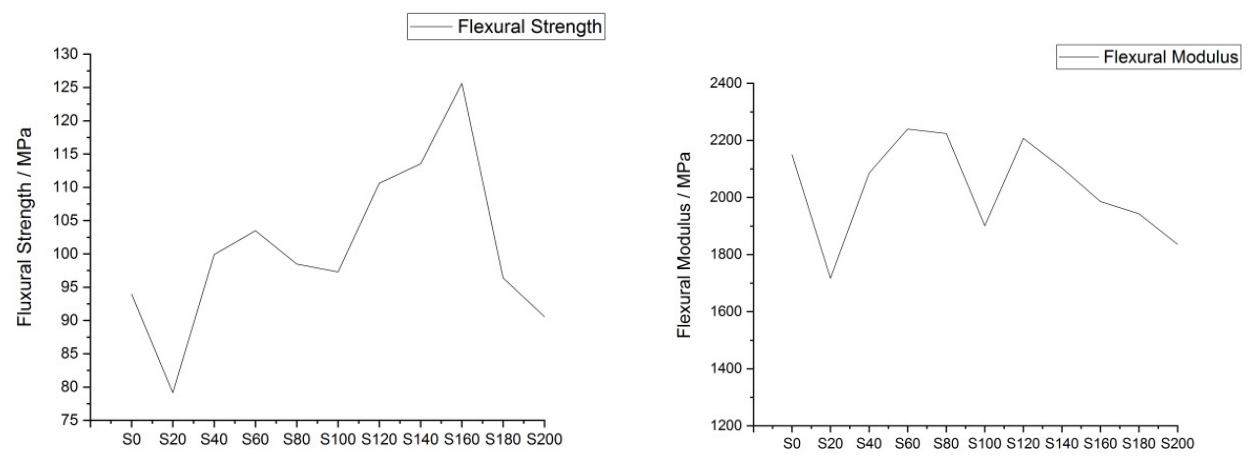

Figure 4. The flexural strength and flexural modulus of different modified epoxy resins 
Data indicates that while the mass percentage of PTMG was less than $16 \%$ of the mass of epoxy resin, the flexural strength of the cured epoxy resin increased significantly, while the change of flexural modulus was not significant. When the mass ratio between PTMG and epoxy resin was 16:100, the flexural strength of the cured epoxy resin mixture reached its maximum of 125.617 MPa. While the mass ratio between PTMG and epoxy resin was greater than 16:100, the flexural strength and the flexural modulus decreased when the mass ratio increased.

\subsection{IMPACT Properties}

Figure 5 shows the correlation of the mass ratio between PTMG and E-51 epoxy resin and the impact strength of the cured material.

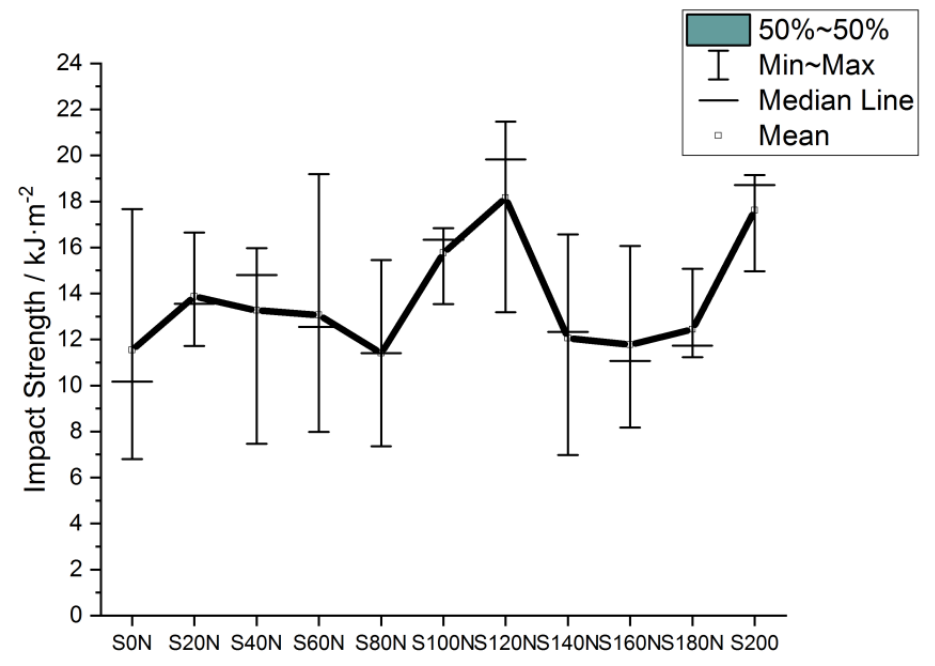

Figure 5. The impact strength of different modified epoxy resins

Data indicates that the impact strength of the cured epoxy resin significantly rose while the mass ratio of PTMG and epoxy resin increased. While the mass ratio between PTMG and E-51 epoxy resin was 12:100, the impact strength of the cured epoxy resin reached its maximum of 18.162 $\mathrm{kJ} \cdot \mathrm{m}^{-2}$. While the mass fraction of PTMG increased when the mass ratio was greater than 12:100, the impact strength of the cured epoxy resins decreased. The increase of impact strength indicates that PTMG toughened the cured E-51 epoxy resin mixture.

The increase in the impact strength was likely caused by the introduction of PTMG-400 chains in the crosslinked polymer network of epoxy resins. The introduction of PTMG-400 increased the flexibility of the epoxy resins, which increased its ability to absorb energy on impact. Therefore, the ability to withstand was improved.

\section{ConClusion}

The addition of PTMG improved the dynamic properties of the epoxy resin mixtures, increasing the tensile strength, tensile modulus, and flexural strength of the epoxy resins.The PTMG toughened epoxy resin reached a maximum tensile strength and tensile modulus when the mass ratio between PTMG and E-51 epoxy resin was 8:100. The PTMG toughened epoxy resin reached a maximum flexural strength when the mass ratio between PTMG and E-51 epoxy resin was 16:100. 
In addition, DMA data shows that the glass transition temperature decreased as the weight ratio of PTMG in epoxy resin increased. The glass transition temperature $\left(T_{g}\right)$ decreased when the mass ratio between PTMG and E-51 epoxy resin increased.

Finally, experiment data shows that PTMG toughened the cured epoxy resin mixtures.The PTMG toughened epoxy resin reached a maximum impact strength when the mass ratio between PTMG and E-51 epoxy resin was 12:100, proving that PTMG can serve as a toughener for epoxy resins. However, There are several limitations to my study. The curing mechanism and the polymer structure was not examined through experiments, which made clarifying the toughening mechanism difficult. In addition, it is observed in this research and other researches that the polymer's physical properties changed while the curing process changed. Therefore, future work can be done on clarifying the structure of the cured epoxy resin mixture, and optimizing the mixture formula and the curing method can also be the aspects of future researches.

\section{REFERENCES}

[1] S. F. Zhao, G. P. Zhang, R. Sun, C. P. Wong, (2013) "Curing kinetics, mechanism and chemorheological behaviorof methanol etherified amino/novolac epoxy systems”, eXPRESS Polymer Letters Vol.8, No.2 (2014) 95-106

[2] D. Carolan, A. Ivankovic, A.J. Kinloch, S. Sprenger, A.C. Taylor, "Toughening of epoxy-based hybrid nanocomposites", Polymer, Vol. 97 (2016)

[3] Y. Q. Cui, W. T. Ye, W. Wei, X. J. Li, J. Luo, X. Y. Liu, (2018) "Study on the synthesis of mikto-arm star polymers and its toughening epoxy resin", Thermosetting Resin Vol. 33 No.4 (2018)

[4] Z. H. Li, Z. Q. Zheng, D. Y. Ren, Y. P. Huang, (2007) "Curing mechanism of TDE-85/MeTHPA epoxy resin modified by polyurethane”, J. Cent. South Univ. Technol. (2007)03-0296-05

[5] Y. Huang, D. L. Hunston, Anthony J. Kinloch, and C. Keith Riew, (1993) "Mechanisms of Toughening ThermosetResins", Advances in Chemistry Vol. 233 (1993) Chapter 1, 1-35

[6] J. B. Dai, H. C. Kuan, X. S. Du, S. C. Dai, and J. Ma, (2009) "Development of a novel toughener for epoxy resins", Polymer International, 58 (2009) 838-845

[7] T. Yang, C. F. Zhang, J. Y. Zhang, J. Cheng, "The influence of tertiary amine accelerators on the curing behaviors of epoxy/anhydride systems", Thermochimica Acta, Vol. 577, 2014, 11-16 (2014)

[8] J. Chen, A.J. Kinloch, S. Sprenger, A.C. Taylor, "The mechanical properties and toughening mechanisms of an epoxy polymer modified with polysiloxane-based core-shell particles", Polymer, Vol. 54, Issue 16 (2013) 4276-4289

[9] L. X. Wang, X. Y. Ma, L. Jin, F. Chen, T. Wu, (2016) "Properties of E-51/DDS Epoxy Resin Toughened by Alkaline EPb-POSS”, Journal of Material Engineering Vol.44, No.11 (2016) 33-38

[10] F. Mustata, N. Tudorachi, "Curing kinetics and thermal characterization of epoxy resin cured with amidodicarboxylic acids”, Applied Thermal Engineering, Vol. 125 (2017)285-296

[11] F. Lei, C.T. Zhang, Z. P. Cai, J. L. Yang, H. Y. Sun, D. Z. Sun, “Epoxy toughening with graphite fluoride: Toward high toughness and strength”,Polymer,Vol. 150 (2018)

[12] D. Incerti, T. Wang, D. Carolan, A. Fergusson, "Curing rate effects on the toughness of epoxy polymers", Polymer, Vol. 159, (2018) 116-123

[13] D.D. Zhang, R. M. Wang, S. Farhan, Y. R. Cai, J. Liu, "Chemorheological behaviors of TDE-85 toughened by low viscosity liquid epoxy for RTM process”,Polymer Testing,Vol. 70, (2018) 310-319 